\title{
Genetic Basis for a Lower Prevalence of Deficient CYP2D6 Oxidative Drug Metabolism Phenotypes in Black Americans ${ }^{1}$
}

\author{
William E. Evans, Mary V. Relling, Atiqur Rahman, Howard L. McLeod, Edward P. Scott, and Jin-Sying Lin \\ Pharmaceutical Department and Biostatistics Department, St. Jude Children's Research Hospital, Memphis, Tennessee 38101; and \\ Center for Pediatric Pharmacokinetics and Therapeutics, Departments of Pediatrics and Clinical Pharmacy, University of Tennessee, \\ Memphis, Tennessee 38101
}

\begin{abstract}
Debrisoquin hydroxylase (CYP2D6) is a cytochrome P450 enzyme that catalyzes the metabolism of $>30$ commonly prescribed medications. Deficiency in CYP2D6 activity, inherited as an autosomal recessive trait, was found to be significantly less common in American blacks (1.9\%) than whites (7.7\%). To determine the genetic basis for this difference, inactivating CYP2D6 mutations were assessed by allele-specific PCR amplification and RFLP analyses of genomic DNA from 126 unrelated whites and 127 unrelated blacks. Blacks had a twofold lower frequency ( 8.5 versus $23 \%, P=<0.001$ ) of the $C Y P 2 D 6(B)$ mutation (point mutation at intron $3 /$ exon 4 splice site), while complete deletion of the CYP2D6 gene (5.5\% blacks, $2.4 \%$ whites), and the CYP2D6( $A)$ mutation (single nucleotide deletion in exon $5 ; 0.24 \%$ blacks, $1.4 \%$ whites) were not different between the two groups. The prevalence of heterozygous genotypes was significantly lower in blacks ( 25 versus $42 \%$ of extensive metabolizers, $P=0.009$ ), consistent with the observed prevalence of the deficient trait in blacks and whites. We conclude that the same CYP2D6 mutations lead to a loss of functional expression in blacks and whites, but American blacks have a lower prevalence of the deficient trait due to a lower frequency of the $C Y P 2 D 6(B)$ mutation. This could explain racial differences in drug effects and disease risk. (J. Clin. Invest. 1993. 91:2150-2154.) Key words: CYP2D6 • pharmacogenetics • ethnic differences • oxidative metabolism
\end{abstract}

\section{Introduction}

Debrisoquin hydroxylase (CYP2D6) ${ }^{2}$ is a cytochrome P450 enzyme that catalyzes the metabolism of $>30$ commonly pre-

Address correspondence to Dr. William E. Evans, St. Jude Children's Research Hospital, 332 N. Lauderdale, Memphis, TN 38101.

Received for publication 10 August 1992 and in revised form 16 December 1992.

1. Given the uncertainty of true ancestry, "black" and "white" are used within this manuscript to designate individuals of presumed African and Caucasian ancestry, respectively.

2. Abbreviations used in this paper: $\mathrm{A}$ or $C Y P 2 D 6(A)$, nonfunctional $C Y P 2 D 6$ with single nucleotide deletion in exon 5; B or $C Y P 2 D 6(B)$, nonfunctional $C Y P 2 D 6$ with point mutation at intron $3 /$ exon 4 splice site; CYP2D6, debrisoquin hydroxylase cytochrome P450; del, complete deletion of $C Y P 2 D 6$ gene; EM, extensive metabolizer phenotype; PM, poor metabolizer phenotype; wt, wild type CYP2D6 allele without known mutations.

J. Clin. Invest.

(C) The American Society for Clinical Investigation, Inc.

$0021-9738 / 93 / 05 / 2150 / 05 \quad \$ 2.00$

Volume 91, May 1993, 2150-2154 scribed medications, including beta receptor antagonists (e.g., metoprolol, propranolol), antiarrhythmics (e.g., encainide, propafenone), antidepressants (imipramine, desipramine), analgesics (e.g., codeine), antitussives (e.g., dextromethorphan ), and antipsychotics (e.g., haloperidol, thioridazine). Previous population studies have shown that $\sim 7-10 \%$ of United States and European Caucasians are deficient in CYP2D6 activity, (1-3) resulting in significantly impaired metabolism of medications that are substrates solely for this enzyme (4-6).

CYP2D6 is under monogenic control and the poor metabolizer (PM) phenotype (i.e., CYP2D6 deficiency) is inherited as an autosomal recessive trait (2). Deficient CYP2D6 activity in PM livers is associated with the absence of immunodetectable CYP2D6 protein (7), which is caused by one of several gene defects (e.g., gene deletion or point mutations/nucleotide changes $)(8,9)$. In Caucasians, two prevalent inactivating mutations in the CYP2D6 gene (CYP2D6) are a point-mutation at the $3^{\prime}$ splice site consensus sequence of intron 3 (CYP2D6 $(B)$ mutation), and a single nucleotide (adenine) deletion in exon $5(C Y P 2 D 6(A)$ mutation $)(10-12)$. Either of these mutations lead to defective mRNA and protein (9), and a deficiency in CYP2D6 activity. A third variant of the CYP2D6 locus leading to the absence of CYP2D6 activity, is a complete deletion of the CYP2D6 gene (13), which is detectable by RFLP analysis $(11.5-\mathrm{kb}$ XbaI restriction fragment) (14).

In a study of 468 unrelated white and 105 unrelated black subjects, we found a significantly lower prevalence of the CYP2D6 deficient trait in American blacks (1.9\%) versus whites $(7.7 \%)(3)$. The fourfold lower prevalence of PM phenotypes in blacks indicates that blacks are less likely to experience exaggerated effects of drugs that are principally inactivated by CYP2D6 (e.g., metoprolol [5], propafenone [4]), are less likely to fail therapy with drugs that must be activated by CYP2D6 (e.g., codeine [15]), and would have a different risk of diseases associated with CYP2D6 phenotype. The present study was undertaken to define the genetic basis for this racial difference in the CYP2D6 poor metabolizer trait.

\section{Methods}

Human subjects. Subjects from whom blood was collected were enrolled from the population of patients, families, and employees at St. Jude Children's Research Hospital, from local schools and from healthy volunteer blood donors. The protocol was approved by the institutional review board for clinical trials. Informed consent was obtained from all subjects over $12 \mathrm{yr}$ of age; parental consent was obtained for all subjects $<18 \mathrm{yr}$ of age. For subjects who had CYP2D6 phenotype determined, a complete medication history for the previous $2 \mathrm{wk}$ and basic demographic and family pedigree data were collected by a nurse. Excluded from the study were subjects with known renal or hepatic disease, those related to another study subject, and those taking 
medications known to induce or inhibit cytochrome P450 enzymes or to be substrates for CYP2D6 (within 2 wk of the study). Subjects were classified as either black or white, based on their statement of race on a questionnaire and its agreement with skin color.

DNA extraction, RFLP, and PCR-based detection of CYP2D6 mutations. In all subjects, $15-30 \mathrm{ml}$ of blood was collected in potassium EDTA tubes; DNA was isolated from leukocytes after proteinase $\mathrm{K}$ digestion, phenol-chloroform extraction, and precipitation with isopropanol/sodium acetate (16).

For identification of the $C Y P 2 D 6(A)$ and $C Y P 2 D 6(B)$ mutations, mutation-specific PCR amplification was performed as previously described (10), with the following modifications. The magnesium concentration was $1.5 \mathrm{mM}$; the concentration of each oligonucleotide primer was $0.125 \mu \mathrm{M}$; Taq polymerase was obtained from PerkinElmer Cetus (Norwalk, CT); and PCR was carried out using a thermocycler (Ericomp, Inc., San Diego, CA). The sequences (5'-3') of oligonucleotide primers to detect the $C Y P 2 D 6(A)$ mutation were as follows (10): first round amplification to isolate appropriate segment of CYP2D6 (2098-3200, numbered according to Kimura et al. [17]) from $C Y P 2 D 7$ and $C Y P 2 D 8$ with primer $A 1=$ GCGGAGCGAGAGACCGAGGA and primer A2 = CCGGCCCTGACACTCCTTCT; second round amplification with A2 plus $\mathrm{A} 3=$ GCTAACTGAGCACA (to amplify only wild type sequences) or A2 plus A4 $=$ GCTAACTGAGCACG (to amplify only mutant sequences). The sequences $\left(5^{\prime}-3^{\prime}\right)$ of oligonucleotide primers to detect the $C Y P 2 D 6(B)$ mutation were as follows: first round amplification to isolate the appropriate segment of $C Y P 2 D 6(1385-2122)$ from $C Y P 2 D 7$ and $C Y P 2 D 8$ with primer $B 1=A T T T C C C A G C T G G A A T C C$ and $B 2=$ GAGACT CCTCGGTCTCTC; second round amplification with B1 plus B3 = CGAAAGGGGCGTCC (to amplify only wild type sequence) or primer B1 plus B4 = CGAAAGGGGCGTCT ( to amplify only mutant sequence).

For identification of the CYP2D6 gene deletion, RFLP analysis was performed (14). DNA (5-10 $\mu \mathrm{g}$ ) was digested to completion with Xbal restriction endonuclease under conditions recommended by the source (New England Biolab, Beverly, MA), and subjected to agarose gel $(0.5 \%)$ electrophoresis. Southern blotting was performed by alkaline transfer to GeneScreen Plus ${ }^{\mathrm{TM}}$ membranes using conditions recommended by the source (DuPont, Boston, MA). The 1.6-kb CYP2D6 cDNA probe (kindly provided by Dr. Frank Gonzalez, National Institutes of Health) was prepared by nick translation with $\left[{ }^{32} \mathrm{P}\right] \mathrm{dCTP}$ $(6,000 \mathrm{Ci} / \mathrm{mmol}$; Amersham Corp., Arlington Heights, IL) to a specific activity of $1-3 \times 10^{8} \mathrm{dpm} / \mu \mathrm{g}$ DNA, hybridized to digested DNA, and the restriction fragment length patterns examined after film exposure for $4-10 \mathrm{~d}$ at $-80^{\circ} \mathrm{C}$. The presence of a band at $11.5 \mathrm{~kb}$ identified the CYP2D6 gene deletion (14).

Determination of CYP2D6 phenotype. After collection of a blank urine sample, dextromethorphan ( $30 \mathrm{mg}$ ) was administered orally to a subset of these subjects, as previously described (18). Urine was collected over the next $4 \mathrm{~h}$, aliquots frozen, and later thawed and assayed by high performance liquid chromatography for dextromethorphan and its polymorphically formed metabolite, dextrorphan (19). The molar concentration ratio of dextromethorphan/dextrorphan was used to assign phenotype, which has been previously shown to exactly co-segregate with that assigned using debrisoquin itself (19). A urinary metabolic ratio $<0.3$ defined extensive metabolizers (EMs) and values $\geq 0.3$ defined subjects with the CYP2D6 deficiency (PMs), consistent with the antimode previously established by population studies of blacks and whites in our laboratory (3) and by others (20). Where dextromethorphan was undetectable because of very extensive metabolism to dextrorphan, the ratio was assigned a value equal to the ratio calculated using the lowest measurable dextromethorphan concentration for each sample; this occurs only in extensive metabolizers.

Statistical analysis. Chi-square analysis was used to assess the difference in proportions (e.g., proportions of homozygous EM genotypes in the blacks versus whites), except when the number of observations was small (e.g., count $<5$ in a cell), for which Fisher's exact test was used. For testing hypotheses about population proportions, such as whether the observed proportion of heterozygous EM genotypes in each racial population agrees with the predicted proportion (based on Hardy-Weinberg calculations), normal approximation to the binomial distribution was used.

\section{Results}

PCR and RFLP analyses were performed on 253 unrelated subjects, 126 whites and 127 blacks. The proportion of males and females was not different in blacks (43\% females) versus whites (45\% females). Assignment of genotype, based on mutation-specific PCR amplification, is exemplified in Fig. 1 for each of the five genotypes detected by PCR. There were 106 whites and 123 blacks with at least one wild type CYP2D6 allele (i.e., EM genotype), and 20 whites and 4 blacks with two mutant alleles for CYP2D6 (i.e., PM genotype). The higher proportion of PM genotypes in the present study, compared to the expected 7.7 and $1.9 \%$, is reflective of efforts to obtain DNA from all consenting subjects identified as a PM phenotype.

As summarized in Table I, a higher percentage of blacks (74.8\%) had a homozygous EM genotype when compared with whites (58.5\%), Chi-square $P=0.009$. As follows, the percentage of heterozygotes among EMs was lower in blacks (25.2\%) than in whites $(41.5 \%)$, Chi-squared $P=0.009$. The percent-

\section{CYP2D6 PCR}

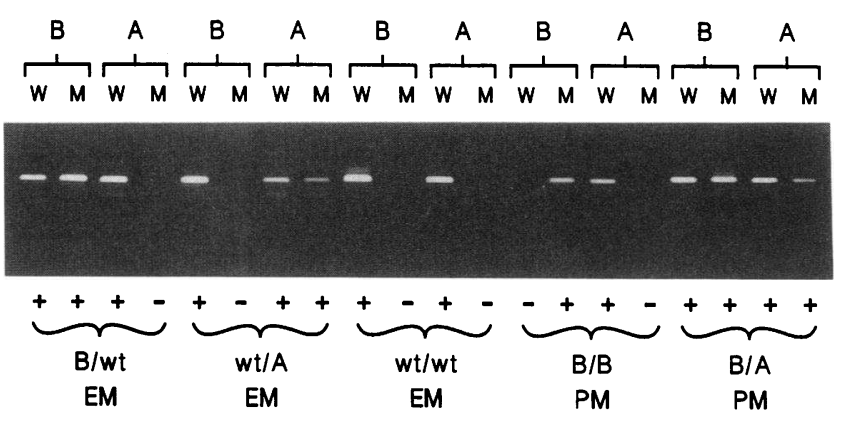

Figure 1. Mutation-specific PCR amplification of the two major inactivating mutations in $C Y P 2 D 6$ gene (i.e., $C Y P 2 D 6[A]$ and $C Y P 2 D 6[B])$. Shown are results using genomic DNA from three individuals who have an extensive metabolizer $(E M)$ phenotype (two heterozygous and one homozygous EMs) and two who have the poor metabolizer $(P M)$ trait. In the upper portion of figure: $B$ and $A$, initial oligonucleotide primers to isolate the segments of $C Y P 2 D 6$ ( from $C Y P 2 D 7$ and $C Y P 2 D 8$ ) which contain either the B or A mutations (i.e., either the region around the intron 3 /exon 4 junction for $B$, or the region around exon 5 for A). After these segments of CYP2D6 have been amplified in the first round of PCR (not shown), different sets of primers are used to detect the presence or absence of mutations; $W$, PCR with oligonucleotide primers identical to the wild type genomic sequence; $M$, oligonucleotide primers identical to the respective mutant gene sequences. In the lower part of the figure indicating genotype: $W t$, wildtype genomic sequence; $A$, amplification with primers recognizing mutation in exon five (single A nucleotide deletion); $B$, amplification with primers recognizing mutation at intron 3 exon 4 splice site (point mutation). Exact sequences of each primer are given in Methods. As depicted, this PCR method allows the assignment of genotype and differentiation of homozygous ( $w t /$ $w t$ ) EM genotypes, heterozygous EM genotypes $(w t / A, w t / B)$, and PM genotypes. RFLP analysis is required to identify the complete deletion of $C Y P 2 D 6$, the third major inactivating mutation at the $C Y P 2 D 6$ locus. 
Table I. CYP2D6 Genotypes in American Blacks and Whites

\begin{tabular}{lcc}
\hline & Whites & Blacks \\
\hline & & (\%) \\
EM genotypes & & \\
wt/wt & $62(58.5)$ & $92(74.8)^{*}$ \\
wt/A & $1(0.9)$ & 0 \\
wt/B & $38(35.9)$ & $19(15.5)$ \\
wt/del & $5(4.7)$ & $12(9.8)$ \\
& $106(100)$ & $123(100)$ \\
PM genotypes & $14(70)$ & $1(25)$ \\
B/B & 0 & 0 \\
A/A & $5(25)$ & 0 \\
A/B & $1(5)$ & $2(50)$ \\
B/del & 0 & $1(25)$ \\
A/del & $20(100)$ & $4(100)$ \\
& & \\
\hline
\end{tabular}

* Proportion of homozygous EMs was significantly higher in blacks than in whites. $P=0.009$, chi-square.

ages of EMs that were heterozygotes are not significantly different from the expected proportions ( $25 \%$ blacks, $44 \%$ whites), based on Hardy-Weinberg calculations for an autosomal recessive trait with a 1.9 and $7.7 \%$ prevalence in blacks (two-sided $P$ $=0.84$, observed vs expected) and whites ( two-sided $P=0.60$ ), respectively (Fig. 2).

The $C Y P 2 D 6(B)$ mutation was the most common mutation found in both white and black EMs, but its prevalence was significantly lower in black EMs ( 7.7 versus $17.9 \%$, Chi-square $P=0.001)$. The CYP2D6 $(A)$ mutation was rare $(<1 \%)$ in both black and white EMs, while the complete deletion of CYP2D6 comprised $4.9 \%$ of alleles in black EMs and $2.4 \%$ of alleles in white EMs (Chi-square $P=0.155$ ).

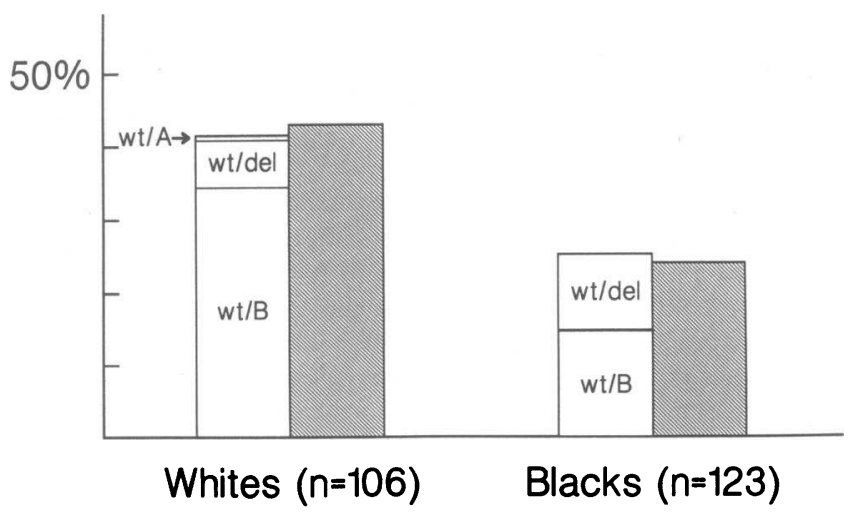

Figure 2. Heterozygous genotypes in blacks and whites. Observed proportion $(\square)$ of whites and blacks with heterozygous EM genotypes, compared to the proportions predicted by Hardy-Weinberg calculations ( $\square$ ) for a 1.9 and $7.7 \%$ prevalence of the recessive (PM) trait in blacks and whites, respectively. Abbreviations for genotypes are as described in Fig. 1. The proportion of heterozygous genotypes was significantly lower in blacks $(P=0.009$, Chi-square $)$, and the prevalence of the $C Y P 2 D 6(B)$ mutation was significantly lower in blacks $(P<0.05)$.
Table II. CYP2D6 Allele Frequencies in American Blacks and Whites

\begin{tabular}{|c|c|c|c|c|c|c|}
\hline \multirow[b]{2}{*}{ Allele } & \multicolumn{2}{|c|}{ PM genotype } & \multicolumn{2}{|c|}{ EM genotype } & \multicolumn{2}{|c|}{ Total population* } \\
\hline & $\begin{array}{c}\text { Blacks } \\
n=8\end{array}$ & $\begin{array}{l}\text { Whites } \\
n=40\end{array}$ & $\begin{array}{c}\text { Blacks } \\
n=246\end{array}$ & $\begin{array}{l}\text { Whites } \\
n=212\end{array}$ & Blacks & Whites \\
\hline Wt & - & - & $\begin{array}{l}0.87^{\ddagger} \\
(215)\end{array}$ & $\begin{array}{l}0.79 \\
(168)\end{array}$ & $0.86^{\ddagger}$ & 0.73 \\
\hline A & $\begin{array}{c}0.125 \\
\text { (1) }\end{array}$ & $\begin{array}{c}0.125 \\
(5)\end{array}$ & - & $\begin{array}{r}0.005 \\
(1)\end{array}$ & 0.0024 & 0.014 \\
\hline B & $\begin{array}{r}0.50^{\ddagger} \\
\quad(4)\end{array}$ & $\begin{array}{c}0.85 \\
(34)\end{array}$ & $\begin{array}{r}0.08^{\ddagger} \\
(19)\end{array}$ & $\begin{array}{c}0.18 \\
(38)\end{array}$ & $0.085^{\ddagger}$ & 0.23 \\
\hline Del & $\begin{array}{c}0.375^{\ddagger} \\
\text { (3) }\end{array}$ & $\begin{array}{c}0.025 \\
\text { (1) }\end{array}$ & $\begin{array}{r}0.049 \\
(12)\end{array}$ & $\begin{array}{r}0.024 \\
(5)\end{array}$ & 0.06 & 0.024 \\
\hline
\end{tabular}

* Allele frequencies in total population based on a $1.9 \%$ and $7.7 \%$ prevalence of the poor metabolizer trait in blacks and whites, respectively (i.e., sum of values for EMs multiplied by 0.923 [whites] or 0.981 [blacks], and values for PMs by 0.077 [whites] or 0.019 [blacks]). Numbers in parentheses are the number of alleles assessed by PCR and RFLP analyses. ${ }^{\ddagger} P<0.05$, blacks versus whites.

Table II summarizes the CYP2D6 allele frequencies in all black and white subjects with PM genotypes, EM genotypes, and values extrapolated to the total population of blacks and whites. The frequency of mutant alleles was $14.3 \%$ for the black population versus $26.9 \%$ for the white population $(P<0.001)$. The lower frequency of mutant alleles in blacks was due almost entirely to a lower frequency of the $C Y P 2 D 6(B)$ mutation ( $8.5 \%$ vs $23 \%, P<0.001)$.

The mutations found in all black $(n=4)$ and white ( $n$ $=20$ ) subjects with a PM genotype are also summarized in Table II. The $C Y P 2 D 6(B)$ mutation was again the most prevalent mutation in both blacks and whites, accounting for $85 \%$ of mutant alleles in white PMs and 50\% in black PMs (Fisher's exact $P=0.047)$. The $C Y P 2 D 6(A)$ mutation accounted for $12.5 \%$ of alleles in both black and white subjects with PM genotypes, while the complete deletion of CYP2D6 represented $37.5 \%$ of alleles in black PMs and $2.5 \%$ of alleles in white PMs (Fisher's exact $P=0.012$ ).

CYP2D6 phenotype was determined using dextromethorphan in 89 whites and 70 blacks with EM genotypes, and in 20 whites and 2 blacks with PM genotypes. The remainder of subjects were blood donors who did not participate in the clinical phenotyping studies $(n=72)$. In the subset of 181 subjects in whom clinical phenotype was determined, all 22 subjects with PM genotypes had a PM phenotype, while 154 of 159 subjects (96.9\%) with EM genotypes had EM phenotypes. The lack of concordance between genotype and phenotype in five subjects (3\%) with a wild type allele but a PM phenotype (four whites, one black), could be due to imprecision in phenotype assignment or to the presence of rare CYP2D6 inactivating mutations, which are not detected by current PCR and RFLP analyses (11).

\section{Discussion}

This study has established that blacks in the southeast United States have a lower frequency of CYP2D6 mutant alleles, yielding a lower prevalence of the autosomal recessive debrisoquin 
hydroxylase (CYP2D6) poor metabolizer trait. The present molecular studies were initiated after our clinical study revealed a 1.9\% prevalence of the CYP2D6 PM trait in American blacks compared to a $7.7 \%$ prevalence in whites (3). According to Hardy-Weinberg calculations, the expected proportion of homozygous EMs in the entire population would be $74 \%$ for blacks and 52\% for whites, if the PM trait has a true prevalence of 1.9 and $7.7 \%$, respectively. Thus, the expected proportion of homozygous individuals within only the subset of individuals who are EMs would be $75 \%$ for blacks and $56 \%$ for whites, values in close agreement with those found in the present study (i.e., 74.8 and $58.5 \%$ ). Therefore, the present study establishes a genetic basis for our clinical finding of a significant difference in CYP2D6 drug metabolism phenotypes in these two ethnic groups in the United States.

The present study has also established that the three major CYP2D6 inactivating mutations previously recognized in Caucasian populations $(11,12,21)$, are also present in the black population. The lower overall prevalence of mutant alleles in blacks was due to a significantly lower frequency of the $C Y P 2 D 6(B)$ mutation in blacks $(8.5$ vs. $23 \%)$ while the frequencies of the CYP2D6(A) mutation and the gene deletion were similar in both groups. That all evaluable subjects who carried two of these mutations were found to have a PM phenotype, demonstrates that these are inactivating mutations in both racial groups.

Ethnic differences in drug metabolism phenotypes were recognized > $30 \mathrm{yr}$ ago, and have now been documented for $\mathrm{N}$ acetyltransferase in Asians and Caucasians (22), mephenytoin hydroxylation in Asians and Caucasians (23), and debrisoquin hydroxylase (CYP2D6) phenotypes in American blacks and whites (3) and in Asians and Caucasians (23). The genetic basis for these ethnic differences in cytochrome P450 enzymes has not been precisely defined. The present study has established that the difference in CYP2D6 drug metabolism phenotypes in American blacks and whites is due to genetic differences, and not environmental or other causes. Specifically, this ethnic difference in CYP2D6 phenotypes is due to a twofold lower frequency of the $C Y P 2 D 6(B)$ mutation in blacks. This mutation of $C Y P 2 D 6$ has been reported to comprise 22 and $27 \%$ of alleles in two studies of European Caucasians $(12,20)$, an allele frequency similar to that found in our white subjects ( $23 \%$ ), but greater than the $8.5 \%$ of alleles in our black population ( Table II ). The frequencies of $C Y P 2 D 6(A)$ mutations and of complete deletion of the $C Y P 2 D 6$ gene were low in the European Caucasian populations, as was the case in our white and black populations. The frequency of wild type CYP2D6 alleles was $74 \%$ in both studies of European Caucasians, similar to the $73 \%$ found in our white population, but lower than the $86 \%$ frequency of wildtype alleles in our black population. Thus, CYP2D6 mutations in our white population are comparable to reports of two European Caucasian populations, but the frequency of $C Y P 2 D 6(B)$ mutations in our black population differs from all white populations reported to date.

The anthropology of these genetic differences is not known, but could be related to the introduction of Caucasian genes into the genome of American blacks. It has been reported that 20-25\% of genes in some American black populations are from Caucasian ancestry, based on either $\mathrm{ABO}$ or $\mathrm{F} y^{\mathrm{a}}$ allele frequencies (24). Moreover, several clinical studies have reported a very low prevalence of the CYP2D6 PM trait in African black populations. For example, the prevalence of CYP2D6 PM phe- notype was found to be 0 in a study of 138 Nigerians (95\% confidence interval $=0-1.4 \%$, using 0.5 instead of 0 to estimate confidence interval), using both debrisoquin and metoprolol to determine phenotype (25). Likewise, Eichelbaum and Woolhouse (26) found 0 of 154 Nigerians to be CYP2D6 poor metabolizers when sparteine was used to assign phenotype. If the true prevalence of the CYP2D6 PM trait were $1 \%$ in the African ancestors of American blacks, then a $25 \%$ penetrance of Caucasian-derived genes in the American black population would be consistent with results in the present study, wherein the same inactivating mutations were present in both populations, but the overall frequency of mutant CYP2D6 alleles was significantly lower in blacks versus whites.

It should be noted that the proportion of Caucasian genes in American black populations may not be the same in all geographical locations in the United States (24). For example, using $\mathrm{F} y^{\mathrm{a}}$ gene frequencies, the proportion in 1969 of Caucasian genes in blacks was higher in nonsouthern cities (e.g., New York, Detroit, Oakland; 19-26\%) compared to southern locations (e.g., Georgia; 11\%) (24). It is not known whether these differences persist in 1992, given the migratory nature of the United States population. Thus, it may be necessary to assess $C Y P 2 D 6$ genotypes and phenotypes in additional black populations, before the present findings can be uniformly extrapolated to other black populations in North America.

Since individuals with the PM trait are more likely to have exaggerated effects with some medications (e.g., metoprolol [5], propafenone [4]) and are more likely to fail therapy with drugs requiring activation by this enzyme (e.g., codeine [15]), these racial differences can be of great therapeutic importance. Moreover, the risk of lung cancer in smokers has been linked to high CYP2D6 activity $(27,28)$ and Parkinson's disease has been associated with a higher frequency of CYP2D6 mutant alleles $(29,30)$ suggesting that ethnic differences at the CYP2D6 locus may also be important for understanding racial differences in the risk of certain diseases. For example, it is an intriguing possibility that the higher prevalence of CYP2D6 wt/wt genotypes contributes to the higher risk of lung cancer among blacks (31). The present study has established that black Americans have a lower frequency of mutant CYP2D6 genes, leading to ethnic diversity in the expression of an enzyme that metabolizes $>30$ commonly prescribed medications, a finding that has both therapeutic and toxicologic implications.

\section{Acknowledgments}

The authors gratefully acknowledge the excellent technical assistance of Pamela McGill, Vicki Green, Emily Melton, Ken Cox, Lisa McNinch, Cynthia Stewart, Margaret Needham, May Chung, Barbara Alexander, and Tanda Grisham, our research nurses Lisa Albonetti, Margaret Edwards, Sheri Ring, Lisa Walters, and Sharon Williams, our computer database managers John Senter and Yuri Yanishevski, members of the medical and pharmacy staffs, the staff of Lifeblood, Inc., Ms. Diane Wilcox for preparation of the manuscript, and, most importantly, the volunteers who participated in this study.

This work was supported by the following awards from the U.S. Public Health Service, National Institutes of Health: R37CA36401, and CORE Cancer Center Support grant CA21765; by a Center of Excellence grant from the State of Tennessee; by an endowment from the First Tennessee Bank, and by American Lebanese Syrian Associated Charities (ALSAC). 


\section{References}

1. Mahgoub, A., J. R. Idle, L. G. Dring, R. Lancaster, and R. L. Smith. 1977. Polymorphic hydroxylation of debrisoquine in man. Lancet. ii:584-586.

2. Eichelbaum, M., N. Spannbrucker, B. Steincke, and H. J. Dengler. 1979.

Defective N-oxidation of sparteine in man: a new pharmacogenetic defect. Eur. J. Clin. Pharmacol. 16:183-187.

3. Relling, M. V., J. Cherrie, M. J. Schell, W. P. Petros, W. H. Meyer, and W. E. Evans. 1991. Lower prevalence of the debrisoquin oxidative poor metabolizer phenotype in American blacks versus whites. Clin. Pharmacol. Ther. $50: 308-313$

4. Lee, J. T., H. K. Kroemer, D. J. Silberstein, C. Funck-Brentano, M. D. Lineberry, A. J. J. Wood, D. M. Roden, and R. L. Woosley. 1990. The role of genetically determined polymorphic drug metabolism in the beta-blockade produced by propafenone. $N$. Engl. J. Med. 322:1764-1768.

5. Lennard, M. S., J. H. Silas, S. Freestone, L. E. Ramsay, G. T. Tucker, and H. F. Woods. 1982. Oxidation phenotype-a major determinant of metoprolol metabolism and response. $N$. Engl. J. Med. 307:1558-1560.

6. Brøsen, K., and L. F. Gram. 1989. Clinical significance of the sparteine/debrisoquine oxidation polymorphism. Eur. J. Clin. Pharmacol. 36:537-547.

7. Zanger, U. M., F. Vilbois, J. P. Hardwick, and U. A. Meyer. 1988. Absence of hepatic cytochrome P450bu f I causes genetically deficient debrisoquin oxidation in man. Biochemistry. 27:5447-5454.

8. Gonzalez, F. J., R. C. Skoda, S. Kimura, M. Umeno, U. M. Zanger, D. W. Nebert, H. V. Gelboin, J. P. Hardwick, and U. A. Meyer. 1988. Characterization of the common genetic defect in humans deficient in debrisoquine metabolism. Nature (Lond.). 331:442-446.

9. Kagimoto, M., M. Heim, K. Kagimoto, T. Zeugin, and U. A. Meyer. 1990. Multiple mutations of the human cytochrome P450IID6 gene (CYP2D6) in poor metabolizers of debrisoquine. J. Biol. Chem. 265:17209-17214.

10. Heim, M., and U. A. Meyer. 1990. Genotyping of poor metabolizers of debrisoquine by allele-specific PCR amplification. Lancet. 336:529-532.

11. Evans, W. E., and M. V. Relling. 1991. Concordance of P450 2D6 (debrisoquine hydroxylase) phenotype and genotype: inability of dextromethorphan metabolic ratio to discriminate reliably heterozygous and homozygous extensive metabolizers. Pharmacogenetics. 1:143-148.

12. Broly, F., A. Gaidigk, M. Heim, M. Eichelbaum, K. Mariko, and U. A. Meyer. 1991. Debrisoquine hydroxylase genotype and phenotype. DNA Cell Biol. 10:545-558

13. Gaedigk, A., M. Blum, R. Gaedigk, M. Eichelbaum, and U. A. Meyer. 1991. Deletion of the entire cytochrome P450 CYP2D6 gene as a cause of impaired drug metabolism in poor metabolizers of the debrisoquine/sparteine polymorphism. Am. J. Hum. Genet. 4:943-950.

14. Skoda, R. C., F. J. Gonzalez, A. Demierre, and U. A. Meyer. 1988. Two mutant alleles of the human cytochrome $P 450 \mathrm{dbl}$ gene associated with genetically deficient metabolism of debrisoquine and other drugs. Proc. Natl. Acad. Sci. USA. 85:5240-5243.

15. Sindrup, S. H., K. Brøsen, P. Bjerring, L. Arendt-Nielsen, U. Larsen, H. R. Angelo, and L. F. Gram. 1990. Codeine increases pain thresholds to copper vapor laser stimuli in extensive but not poor metabolizers of sparteine. Clin. Pharmacol. Ther. 48:686-693.
16. DiLella, A. G., and S. L. C. Woo. 1987. Cloning large segments of genomic DNA using cosmid vectors. Methods Enzymol. 152:199-212.

17. Kimura, S., M. Umeno, R. C. Skoda, U. A. Meyer, and F. J. Gonzalez. 1989. The human debrisoquine 4-hydroxylase (CYP2D) locus: sequence and identification of the polymorphic CYP2D6 gene, a related gene, and a pseudogene. Am. J. Hum. Genet. 45:889-904.

18. Evans, W. E., M. V. Relling, W. P. Petros, W. H. Meyer, J. Mirro, and W. R. Crom. 1989. Dextromethorphan and caffeine as probes for simultaneous determination of debrisoquin-oxidation and $\mathrm{N}$-acetylation phenotypes in children. Clin. Pharmacol. Ther. 45:568-573.

19. Park, Y. H., M. P. Kullberg, and O. N. Hinsvark. 1984. Quantitative determination of dextromethorphan and three metabolites in urine by reversephase high performance liquid chromatography. J. Pharm. Sci. 73:24-29.

20. Schmid, B., J. Bircher, R. Preisig, and A. Küpfer. 1985. Polymorphic dextromethorphan metabolism: co-segregation of oxidative O-demethylation with debrisoquin hydroxylation. Clin. Pharmacol. Ther. 38:618-624.

21. Dahl, M.-L., I. Johansson, M. P. Palmertz, M. Ingelman-Sundberg, and F. Sjoqvist. 1992. Analysis of the CYP2D6 gene in relation to debrisoquin and desipramine hydroxylation in a Swedish population. Clin. Pharmacol. Ther. 51:12-17

22. Sunahara, S., M. Urano, and M. Ogawa. 1961. Genetical and geographic studies on isoniazide inactivation. Science (Wash. DC). 134:1530-1532.

23. Nakamura, K., F. Goto, W. A. Ray, C. B. McAllister, E. Jacqz, G. R. Wilkinson, and R. A. Branch. 1985. Interethnic differences in genetic polymorphism of debrisoquin and mephenytoin hydroxylation between Japanese and Caucasian populations. Clin. Pharmacol. Ther. 38:402-408.

24. Reed, T. E. 1969. Caucasian genes in the American Negro. Science (Wash. DC). 165:762-768

25. Iyun, A. O., M. S. Lennard, G. T. Tucker, and H. F. Woods. 1986. Metoprolol and debrisoquin metabolism in Nigerians: lack of evidence for polymorphic oxidation. Clin. Pharmacol. Ther. 40:387-394.

26. Eichelbaum, M., and N. M. Woolhouse. 1985. Inter-ethnic difference in sparteine oxidation among Ghanaians and Germans. Eur. J. Clin. Pharmacol. 28:79-83

27. Ayesh, R., J. R. Idle, J. C. Ritchie, M. J. Crothers, and M. R. Hetzel. 1984. Metabolic oxidation phenotypes as markers for susceptibility to lung cancer. Nature (Lond.). 312:169-170.

28. Caporaso, N. E., M. A. Tucher, R. N. Hoover, R. B. Hayes, L. W. Pickle, H. J. Issaq, G. M. Muschik, L. Green-Gallo, D. Buivys, S. Aisner, et al. 1990. Lung cancer and the debrisoquine metabolic phenotype. J. Natl. Cancer Inst. 82:1264-1272.

29. Armstrong, M., A. K. Daly, S. Cholerton, D. N. Bateman, and J. R. Idle. 1992. Mutant debrisoquine hydroxylation genes in Parkinson's disease. Lancet. 339:1017-1018.

30. Smith, C. A. D., A. C. Gough, P. N. Leigh, B. Summers, A. E. Harding, D. M. Maranganore, S. G. Sturman, H. V. Schapira, A. C. Williams, N. K. Spurr, and C. R. Wolf. Debrisoquine hydroxylase gene polymorphism and susceptibility to Parkinson's disease. Lancet. 339:1375-1377.

31. Devesa, S. S., W. J. Blot, and J. F. Fraumeni. 1989. Declining lung cancer rates among young men and women in the United States: a cohort analysis. $J$. Natl. Cancer Inst. 81:1568-1571. 